\title{
Conversaciones con OMAR Rincón
}

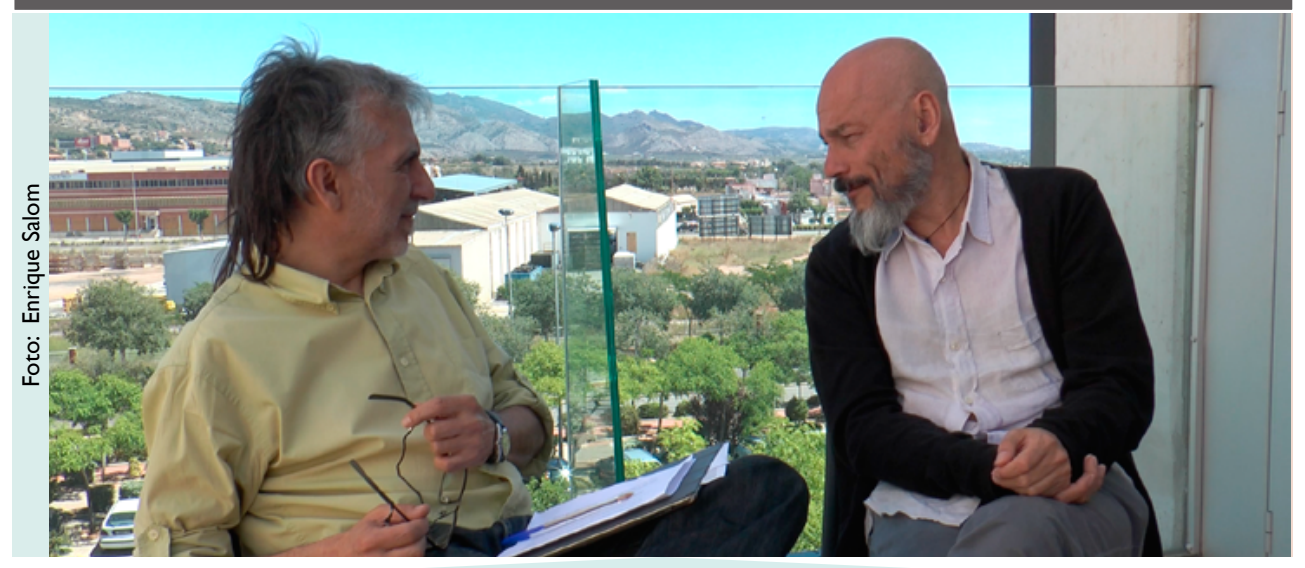

Omar Rincón: Me gustó el concepto que manejo últimamente, por molestar teóricamente, yo creo que hay que hablar de culturas bastardas. García Canclini habla de «culturas híbridas», Martín Barbero de las «mediaciones», si vamos a Bajtim las «cronotopias», Fernández Laporta propone el «Sampler»... Es decir, todos proponen figuras de mezcla.

JoAN Traver (KULT-UR): [...] de saberes fronterizos.

OR: Pero la mayoría proponen mezclas buenas, lo indígena con lo blanco, lo femenino con lo transexual... es decir, mezclas políticamente buenas. Y ésas están bien, pero pierden mucho los términos en identidades difusas, en contenidos ambiguos. En cambio, a mí me parece que estamos hechos de unas mezclas totalmente impuras, ilegítimas, sucias... Por eso uso el concepto culturas bastardas, ya que tenemos unas mezclas de las que ninguno mismo es consciente o son políticamente correctas. Antes de una entrevista no sé cómo voy a actuar frente a la cámara, cómo voy a estar... por más control que tenga de las condiciones de producción, lo que sale es un ponerse en acto bastardo; uno que indica que tengo incidencia de la cultura gringa porque he visto mucha televisión gringa y películas, pero también incidencia de la cultura latina porque soy más expresivo, además de incidencia de la cultura televisiva que me produce mirando a la cámara. Y también decide cómo me pongo en escena, hoy por ejemplo, me pongo una camisa porque tengo que dar una conferencia... y así parezco mas conferencista. 
JT: A mí me ha gustado toda la parte que estabas comentando. Enfocamos esto como una entrevista o como una charla. Yo tenía ganas de conocerte por lo que te había leído, por los referentes, como bien dices, Rafa Miralles es un buen publicista tuyo, y le tengo mucho cariño. Las cosas que vienen de él, sean puras o impuras, las agradezco.

OR: Somos impuros... ¿Qué significa lo de las culturas bastardas? Queramos o no, somos hijos de la cultura pop, por más que le huyamos, hemos visto Hollywood, hemos bailado o tarareado éxitos a lo gringo, hemos leído bestsellers, hemos visto televisión, series de televisión, hemos habitado nuestras culturas populares. No podemos renunciar a eso, por más que queramos ser puros. Por intentar la pureza, Europa le hace un gran favor a Hollywood: no le lucha el público. Es más, Hollywood podría financiar todo el cine independiente europeo, porque mientras sigan haciendo cine de autor que no quiere competirles, Hollywood es feliz: le dejan el público a ellos. Sigan ustedes haciendo cine francés, sigan ustedes haciendo cine español, allá para su ghetto, y que lo financie el Estado. Perfecto. Pero el público me lo dejan a mí. O sea, que somos sujetos del gusto impuro, y las culturas del espectáculo hacen buen negocio de eso: nos cuentan y gozan con nuestros gustos establecidos. Y lo llamo culturas bastardas porque somos hijos de muchos padres: el cine de Hollywood, la música pop, el cine pop, toda la Pop-Culture... pero también nuestras lecturas, arte y textos... pero también nuestras herencias culturales ancestrales y populares. Ustedes aquí en Valencia vienen con el territorio, con la historia... pero también con el pensamiento de lo femenino, lo transexual, lo español... Pero también somos hijos de lo más bizarro, los artistas bizarros que toman a la gente más loca del mundo y muestran los enfermos sociales del mundo contemporáneo. Y también somos hijos del capitalismo. Somos hijos de muchas partes, pero al ser bastardos impuros hay una sola cosa pura.

JT: ¿Cuál?

OR: La madre. Esto no lo podemos cambiar, porque siempre hemos sido hijos de una madre, que es la madre cultural local. Y es desde ahí que enunciamos, expresamos, mezclamos, mixturamos.

JT: Ya... 
OR: Entonces, lo de las culturas bastardas lo que enfatiza es la necesidad de crear desde lo local asumiendo todas las impurezas que tengamos, sabiendo que lo que te da sentido es crear de y desde lo local, y eso es lo que constituye la fuerza de lo popular y también del arte. Eso está ahí, es la fuerza de un Dalí o un Miró, o el mismo Calatrava con todas las bobadas que hace, está hecho de empatizar lo local en un hecho del mundo, y por eso las músicas son tan fuertes, porque se mezclan. Hay flamenco-pop, flamenco-electrónico, flamenco-tango, y esa mezcla permite que el flamenco sobreviva. Si el flamenco estuviera quieto y puro, sin aceptar impurezas, terminaría por diluirse.

JT: Tú defiendes ese dinamismo, de alguna manera...

OR: Claro, es que es la única forma de existir culturalmente.

JT: Y es la única vía para construir identidad.

OR: Sí, por eso me gustó la idea de ustedes de «Nómadas» y lo local. Porque es eso. Lo bastardo, lo nómada, lo que se mueve. Y lo local es lo que ancla y da sentido. Y aparece un concepto que me parece chévere que lo mencionaste porque me quería opinar de una cosa: el concepto de interculturalidad. Es un concepto vendido raramente, es como un debate que es: frente a lo multicultural (tú estás aquí y yo estoy allí, indígena, negro, transexual, ambientalista...) que indica que estamos juntos pero no revueltos; que reconoce la diferencia, pero no se mezcla... Está lo intercultural que implica la mezcla y la intervención y la interferencia; lo intercultural tiene una virtud bellísima como concepto: el obligarse a hacerse desde y con el otro, los otros culturales fuertes como son lo indígena, lo oriental, lo femenino, las nuevas sexualidades. Acerca de lo intercultural en Bolivia me llamaron la atención. Y tienen toda la autoridad para hacerlo porque es el único lugar del mundo que ha elevado a rango constitucional la interculturalidad. Ellos no se llaman «República de Bolivia», como hay tantas Repúblicas, sino «Estado plurinacional de Bolivia». Ya rompe con la idea de república y asume la interculturalidad desde el nombre mismo de la nación. Allá, dando un taller sobre interculturalidad, aprendí que dicha interculturalidad implica tomar el cuerpo del otro, y no siempre en una relación de respeto sino de hacerse con el otro, intervenir el uno desde el otro. Por ejemplo, a ellos les parece racista la categoría mestizo, que a nosotros nos parecía muy bien. Yo mismo soy mestizo: tengo lo indígena, lo español, lo blanquito, lo negro, y me mezclo. Y me decían que es una categoría cómoda: en el mestizaje cabe todo, luego no te permite hacer 
una afirmación de tu identidad. Para ser intercultural tienes que afirmar tu identidad respecto a otros, y determinar un lugar en el mundo de cómo te ubicas frente a eso. En Bolivia, por tanto, decidieron que hay que buscar adscripciones de tu identidad para que te juegues políticamente, y te ofrecen treinta y cuatro adscripciones de identidad para que decidas en cuál te quieres jugar.

JT: Y desde ese juego construir ese concepto de interculturalidad.

OR: Hay una interculturalidad mucho más grande, ya que tienes treinta y cuatro opciones. En el mundo nuestro, colombiano-latino, tenemos: indígena, afro, mestizo, zambo y blanco. Es decir, cinco. Como no tengo nada de Afro ni nada de zambo - lo cual me ha pesado porque ojalá tuviera algo del sabor caribe, sería lo máximo - tengo que buscar el afro que llevo dentro. En la interculturalidad agenciamos mas subjetividades.

\section{"Hay que asumir la incomodidad como manera de pensar lo cultu- ral, y creo que ahí tiene sentido la interculturalidad.»}

JT: Tú estás en las intersecciones, por decirlo de alguna forma.

OR: Sí, exacto. Me gusta eso. Si soy mestizo, me quedo en la mitad, esta afirmación es muy cómoda. Y la interculturalidad tiene que incomodarte, que es la otra parte que es interesante: intersecciones, incomodidades, mutaciones. Hay que asumir la incomodidad como manera de pensar lo cultural, y creo que ahí tiene sentido la interculturalidad. Por eso digo que me preocupa porque mucha gente lo asume como un lugar cómodo para evitar el mundo: «Es que yo soy intercultural».

JT: La interculturalidad nace del conflicto... por lo que tú estás comentando.

OR: Sí, exacto.

JT: Nace del choque.

OR: De asumir que el conflicto es parte vital de la producción de la identidad, de la producción de la subjetividad, de la producción de la colectividad y — ese nuevo concepto ahora - de la producción de la agencia 
política. Me gusta eso. Me gusta practicar la Academia bastarda, de mutación, de virus, de intersección...

JT: ¿Qué papel juegan los medios ahí, desde tu punto de vista?

OR: Los medios son una cosa alucinantemente pero estabiliza. No se pueden negar: se es para narrar, se vinculan presencias prototípicas. Pero así mismo, no podemos ser desmediatizados ni remediatizados. Están. Somos. Es un asunto del que tenemos que hacernos cargo, como de la contaminación ambiental, como el verano o como el agua. Están ahí. La versión de que huyamos de los medios no es posible. Están. Por tanto, creo que hay que asumir otras maneras de interacción con los medios. Y la primera que habría que asumir hoy es intervenirlos: producirlos. La forma de ganar a los medios es «no los vea, hágalos» y esa posibilidad es la que tenemos.

JT: Tú lo defiendes. Coge tu cámara...

OR: Sí, hazlo. Hoy no tienes por qué decir: «Es que la televisión es una mierda y una basura». Pues apáguela y coja el teléfono, grabe y póngalo en Youtube y vea Youtube. Hoy en día no se vale decir «eso es bueno» y tampoco se vale lo otro, que es el ilustrado que decide qué es lo que hay que ver. Al diablo el dios de los dualismos, bienvenido el diablo de lo ambiguo. El ilustrado por derecha, por izquierda, por religión es dualista. La izquierda que quiere que la gente vea mensajes revolucionarios y construya su propia significación del mundo, o del de derechas que quiere que la gente no vea sexo, porno-miseria, porque se acaba y peca contra Dios, o el de derechas que quiere que simplemente la gente vea basura para que no piense y se mantenga en su estupidez. Ninguno. Ninguno de los tres funciona. Tenemos que buscar la ambigüedad, la intervención de eso, el jugar con este tipo de cosas; y también ver estupideces. Una de las grandes virtudes televisivas es que la televisión es el único medio que hay, el único lugar en el mundo que la sociedad occidental tenemos para ser estúpidos. Y eso también es válido para la vida. Es muy difícil ser inteligente todo el día. Hay que ser inteligente para levantarse a tiempo, para tomar el transporte público o el privado para llegar al trabajo. Hay que ser inteligente también en el trabajo, y también para alimentarse bien para no engordar. Se tiene que ser inteligente para todo, hasta para el sexo y el amor. Y hay un momento del día en el que llegas a casa y la pantalla de televisión te dice: «Aquí puedes dejar el cerebro en la mesilla y entrar en la pantalla como relajación». Eso es lo lindo de ver una telenovela o un partido de fútbol. Uno no está 
siendo estúpido, sino que está relajando, distensionando, entrando en un zen. Podríamos cambiarlo por la contemplación. Hagamos yoga y veamos el cielo azul durante quince minutos: el mismo efecto.

JT: Tú defendías eso mismo, las narrativas light en la televisión.

OR: Es que, ¿por qué tiene todo que narrar como la educación? La profundidad está sobrevendida. Tú que vienes de la Educación. Su gran error es que quiere educarnos a todos todo el tiempo. Y ya, lo decía Lucas, el hijo de la que era mi novia, que a los ocho años me decía: «Omarito, yo soy un niño juicioso en el colegio (y es verdad, le va bien, es la mejor nota) pero estoy aburrido de que quieran educarme todo el tiempo. Prendo el televisor y quieren educarme, juego a un videojuego y quieren educarme, voy a un restaurante y quieren educarme... ¡Y Ya no más!». Es decir: «Yo cumplo con la educación, pero no me eduquen todo el tiempo». Y esa obsesión es autoritaria porque si alguien cree que hay que educar es porque él cree que él sabe y que el otro no sabe. No parte de un principio de que el Otro te puede enseñar, sino que yo tengo que enseñarte a ver televisión, enseñarte a jugar por internet, etc. Así parece que la educación hoy tiene que comenzar a practicar la confianza en el Otro, en que el Otro tiene un saber y que también es válido y también tiene tiempo de ocio, tiempo de saber, tiempo de disfrute, tiempo de juego, y que ese juego también es educación.

\section{"Lo que sucedió en el siglo xx con la llegada del cine y en el xxi con internet, es que el entretenimiento se volvió el centro, la forma cen- tral de la sociedad contemporánea. "}

JT: Tú, desde ese punto de vista enfatizabas bastante el peso de lo emocional, de lo emotivo, en ese tipo de narrativas, en conforme llegan... ¿Dónde queda lo racional?

OR: El problema que tenemos con todo el triunfo de la forma de entretenimiento es que siempre ha existido, pero siempre al margen. Lo que sucedió en el siglo xx con la llegada del cine y en el XXI con internet, es que el entretenimiento se volvió el centro, la forma central de la sociedad contemporánea. Al margen queda el arte, lo racional, y las cosas densas de la modernidad ilustrada. Eso significa que entonces debemos ir a su rescate, pero eso no puede ser el rescate de uno contra el otro, sino el rescate desde la forma de entretenimiento porque es como podemos 
recuperar una nueva forma de arte, una nueva forma de racionalidad, etc. Ahí sí, como decimos, lo intercultural sería el inter-pensamiento. Y es que no puedo eliminar lo racional solamente por enfatizar lo emocional, sino que forma parte de una interrelación-interfaz distinto. Arturo Escobar, un gran pensador de lo intercultural, lo llama sentipensar. Y Milan Kundera decía que el problema de la imagología es que pasaba primero por el corazón para llegar al cerebro. Adorno decía que el problema en la obra de arte era que en la obra estaban todos los significados y el sujeto no contaba. Hoy resulta que todo el significado está en el contexto, en la experiencia, en lo corporal. Y de ahí pasa a la cabeza. Yo no puedo explicar nada, llego aquí a Castellón, miro el paisaje, hablo con ustedes y no sé nada de qué pasó aquí. Yo puedo llegar aquí (como un periodista ignorante como lo somos la mayoría) y decir: «como ven la Universidad de Castellón es muy bonita, muy grande. Podríamos decir que parece una universidad privada», porque no sé el contexto, ni cómo se construyó, ni nada de nada, y viendo el paisaje puedo llegar a decir eso. El lunes cuando llegamos no había ningún sitio abierto y todos concluimos que Castellón era muy aburrido. Anoche que nos movieron como cinco cuadras de donde estamos encontramos que sí que hay sitios donde se pasa bien hasta tarde en la noche, pero nos tocó movernos cinco cuadras. Si no nos movemos el contexto no existe. Lo racional sigue existiendo, es que no es que lo eliminemos, sino que hay unas formas otras de producir conocimiento, conocimientos distintos. Yo que estoy en la Universidad me toca producir conocimiento más conceptual, más racional, más argumentativo. Quien está en lo popular produce conocimiento pero vía las historias y relatos y experiencias que produce. Cuando se juntan los dos hacemos un dialogo de saberes porque yo toco todas las experiencias para poder construir algunos conceptos donde aplique algunas teorías y haga sentido. Lo que pasa es que mi lógica de construir conocimiento en la Universidad es más racional argumentativa y la lógica de producir conocimiento en la vida popular es más de historias-experiencias-relato. Entonces no hay ninguna mejor que la otra.

JT: Autores como Sartori decían que asistimos a la emergencia de otro ser humano, el homo videns, que funcionaba más por lo icónico que por lo simbólico.

OR: Hay tantos eslóganes de ésos. Sartori: pasamos del homo sapiens al homo videns. Dejamos de pensar para ver. Otro dicen que pasamos del homo sapiens al homo ludens, dejamos de pensar para jugar. Ahora están hablando del homo sapiens al homo connectus, para decir que 
estamos conectados, pero todo lo tratan como un paso. No es así, somos al tiempo homo ludens, sapiens, ludens, connectus... Todo el mundo quiere enfatizar que dejamos de ser racionales. No podemos dejar de ser racionales porque no hay sociedad más racionalizada que la nuestra. Cada vez somos más racionales. Dejamos de fumar porque nos mata. No somos machistas porque sabemos que hace mal. No comemos grasas porque nos va mal para el cuerpo. Eso es racionalidad. No pasamos el semáforo en rojo. Cumplimos con las reglas. Hoy en día los que somos de más edad cada vez somos más restrictivos porque somos más racionales. Cada vez tenemos más límites. Las condiciones de vida están más limitadas. Hoy nadie se atreve a pegarle a un niño. $\mathrm{O}$ eso espero. Antes se podía pegar a los niños. Eso significa que ahora vivimos con mayor racionalidad. El respeto a los derechos humanos, el respeto al Otro, el pensar antes de actuar... somos más racionales que antes, y a todo eso lo volvimos moralista. Y en eso no estoy de acuerdo. $\mathrm{Ni}$ para un lado ni para el otro. Ni por el moralismo racionalista que dice que lo que yo pienso es bueno y que lo que tú piensas es malo, ni moralismo académico: «Este autor es pésimo, no lo lean, pecado, este autor es Dios, leamos esta cosa». Yo en la Academia tengo que tener el criterio para que el estudiante pueda distinguir que Foucault abre caminos y Benjamin alucina con intuiciones y que Adorno tiene algunos problemas, pero eso no quiere decir que Adorno sea malo. No hagamos juegos morales por religión ni por ideología ni por academia. Tenemos que tener criterios para actuar y así equilibramos la vida. La vida cotidiana es un poco eso: cómo establecemos unos criterios para significar el mundo y establecer cómo nos toca jugar.

JT: Hablando de todo esto, sobre todo de esa cultura más light... Guy Debord habla de la sociedad del espectáculo, ¿Tú pensarías que la sociedad actual esta ahí?, ¿lo ha superado?

OR: Cuando nació el cine, primero hubo un señor llamado Duhamel en el año treinta que dijo que la sociedad se había vuelto espectáculo, y que la gente ya sólo quería ser una celebridad de Hollywood. Año treinta. Después, en el año cuarenta y cuatro, Adorno, que la sociedad espectáculo había tomado el mundo y que la música clásica estaba en decadencia, que Beethoven estaba en decadencia y que el rock y el jazz amenazaban profundamente el mundo. Después, en el sesenta y siete, Debord, con La sociedad del espectáculo describe que la sociedad contemporánea deviene en una forma de espectáculo y que la forma del capital es la colección de espectáculos. Y después Vargas Llosa en el 
2012, trasnochadísimo, casi un siglo después, viene a decir lo mismo. Qué originalidad, siendo que le invitan a dar charlas-espectáculo para vender libros como espectáculo. Lo que Vargas Llosa hace es arte, pero lo que otra gente hace es espectáculo. Entonces, ¿estamos en la sociedad del espectáculo? Sí.

JT: Sí.

OR: Eso es un diagnostico bien hecho por Debord, Duhamel, Adorno y Vargas Llosa, pero con lo que yo y muchos no estamos de acuerdo es con la explicación del fenómeno. Es como si vemos una nube negra sobre Castellón, entonces podemos descubrir que hay una nube negra en Castellón. Ahí hay acuerdo. Si nos preguntamos: «¿Por qué pasa la nube negra?», entonces es donde no estamos de acuerdo, porque estos autores comienzan a decir que el hombre devino leve, banal, frívolo, bárbaro, de mal gusto y de mala estética. Y esto, oiga, para usted, señor ilustrado escritural, está mal. Hay otra vertiente para pensar lo mismo que nace en el año treinta y seis con Walter Benjamin que dice que es la misma queja que han tenido siempre las culturas cuando ven que se acaban, que han perdido su autoridad cultural. Lo que pasa con Adorno y compañía es que han perdido la autoridad para dirigir el destino cultural de una sociedad. Al tener miedo de perder esa autoridad dicen que es diabólico, que apareció el Mal. Y Benjamin dice que hay que dejar de preocuparse de esa queja histórica y hay que comenzar a hacer lo que siempre hay que hacer, es pensar en qué nos estamos convirtiendo. Cuál es el nuevo sensorium. Cuál es la nueva forma de percepción de eso. Y también lo dijo Benjamin en el treinta y seis, bajo ese parámetro, hay una cantidad de gente que ha venido trabajando que es interesante porque dice que hay que analizar la experiencia que se está produciendo de esa nueva civilización. El libro más interesante que hay sobre ello en el momento es uno de Alessandro Baricco, Los Barbaros, publicado en Anagrama, que lo que dice es: «Sí, hay una nueva civilización. Frente a la civilización ilustrada está la civilización de los bárbaros. Pero hay que describir ese sujeto bárbaro en cómo está trabajando y cómo está actuando para describirlo adecuadamente y comprenderlo». Plantea ejemplos muy concretos: «Mientras el sujeto clásico civilizado se concentra en la obra (artística, literaria, arquitectónica), el sujeto bárbaro se preocupa no tanto de la obra como de la secuencia de experiencias que genera la obra».

JT: Es más narrativo. 
OR: Sí, pero además tiene una lógica que es como de los jóvenes de este tiempo: «Yo no tengo que aprenderme todo el libro, sino que tengo que saber a qué experiencia me lleva y en qué secuencia de mundo me deja». Casi que está obligando a que el profesor le explique la secuencia en que va a estar en este libro para que yo lo lea. Antes nos decían: «Tienen que leerse a Joyce», y uno tenía que leerse a Joyce y no decía: «¿Para qué?». Hoy el profesor tiene que decir: «Lea a Joyce, de la página veinticinco a treinta, para que usted entienda el concepto que había en los años treinta de ser humano y para que entienda cómo hemos perdido un tipo de espíritu».

JT: Ya...

OR: [...] y entonces lo leo para ver eso. Pero tengo que poderte provocar. En cambio, el profesor clásico te lo hacía leer porque tocaba leerlo. No. O que tocaba memorizar. Y los jóvenes ya lo dicen: «¿Para qué tengo que memorizar si está en internet?, dígame qué relaciones debo construir sobre esto que usted me pide».

JT: Yo, por ejemplo, uno de los elementos que jugaría fuerte en esa secuencia sería el papel de lo emotivo. De lo emocional.

OR: Pero lo emocional no es racional. Yo tengo que darte buenas razones y eso es complicadísimo. Yo tengo que decirte buenas razones para llevar a que tú tengas una buena experiencia y esa experiencia sea emocional pero también racional. Tengo que proveerte de un rango de emociones, también.

JT: Yo lo decía más centrado en lo que se define como «Cultura del espectáculo». La sociedad del espectáculo.

OR: La sociedad del espectáculo de alguna forma lo que hace es proponerte una cantidad enorme de emociones y de espectáculos banales y de ficciones de experiencias.

JT: Emotivos. Ese componente lo tienen.

OR: Son emocionales pero también son racionales en el sentido en que, por ejemplo, ir a un concierto es emocional en cuanto al acto de estar allí, pero la cantidad de normas racionales de comportamiento que tenemos es enorme. Y además tenemos normas racionales de concepto de riqueza, como las personas que bajan 7000 películas, que no saben cuándo van a verlas, pero hay una racionalidad en el «bajar películas». 
Hay gente que colecciona conciertos. Y hay una racionalidad de qué conciertos te dan un valor y qué no te da un valor. Hay un juego racional de economía cultural. Lo emocional es la entrada a la experiencia. Sin emoción no hay experiencia, obvio esto; en cualquier obra de arte...

JT: Si se enfatizaba mucho únicamente lo racional, lo emocional parece que quedaba fuera. En el juego escolar, por ejemplo, ese movimiento pendular estaba, ¿no?

OR: Sí, pero lo que se hacía en el juego escolar es que se enfatizaba en el saldo pedagógico de juego. Pero en el fondo uno sabía que jugaba porque era divertido. Dicho para que no sea solamente blanco o negro, es una cosa que dice Maffesoli, es que necesitamos re-sacralizar el mundo, re-ritualizar el mundo. Y es un valor también importantísimo. Si fuéramos racionales todo el tiempo, veríamos pasar un auto y pensaríamos «masa por aceleración al cuadrado, me tengo que desplazar a tal velocidad para que el auto no me pille». Necesitamos crear rituales. Por tanto, en esa re-ritualización del mundo, como la religión perdió todo su lugar de ritualización, como la educación ha matado la ritualización, todo lo hemos desritualizado. La sociedad de entretenimiento sí es capaz de crear esos rituales.

JT: Y cerca de esa «sociedad del entretenimiento», ¿cómo ves el papel de los populismos?

OR: El populismo es una forma de re-ritualizar la política. Por eso los populismos no deben definirse como un asunto de izquierda como hacen los teóricos sino como una forma de gobierno como lo enfoca Laclau. Es una forma de gobernar, una forma de hacer política, y está basado en criterios de recuperar... En una definición muy elemental, es una manera de meterle pueblo a la democracia. De ciudadanizar la democracia. Con los ciudadanos que tengamos. Si aquí (en España) son mucho más cómodos pero tecnologizados que lo que se hace por ahí. En América Latina tenemos unos ciudadanos no tan tecnologizados pero mucho más incómodos, y se hace por ahí. De alguna forma el populismo es una re-ritualización del mundo y es un elemento que además recuerda que la política está siempre hecha de pueblo y que la política estuvo hecha de fiesta, y que siempre estuvo hecha de contrato social. La política racional, ésa que dicen en los grandes discursos, se ha venido diluyendo (si es que alguna vez haya existido). Cuando le dicen a uno que existió se pregunta: «¿Dónde, dónde estuvo el gran gobernante racional, programático, coherente?»; y yo no lo sé. Yo no los he visto. 
JT: ¿En las propuestas populistas no se pierde también, de alguna forma, esa identidad fuerte que tú reclamas?

OR: Sí, se diluye esa identidad fuerte.

JT: Y además se diluye también el conflicto de alguna forma.

OR: No, se asume el conflicto desde otro lugar, que es terriblemente positivo en criterio de narración pero es también terriblemente frustrante en términos políticos. Porque me propone asumir el conflicto de la vida social desde otro lugar. Diciendo que todo lo que está no sirve. Entonces se plantea una utopía en la que - entre yo, gobernante, y tú, pueblo - vamos a solucionar ese tipo de cosas. Pero en medio está la jurásica institucionalidad que no te permite actuar. Tú entras y la institucionalidad te mata, que es lo que está pasando en Grecia. La gente vota por un sujeto y por un partido y por una opción. Pero el tipo no puede salirse del préstamo de la UE. La institucionalidad es tan fuerte que te mata, te limita. Te mata las pasiones. El conflicto está bien planteado pero la resolución del conflicto está en problemas porque la institucionalidad es muy testaruda y gana por presencia. Es como el sistema educativo. ¿Cuántas veces se ha diagnosticado la muerte de la educación? La Universidad nació en el siglo XVI. Desde allí, cada cien años la Universidad muere. Y no ha podido ser reemplazada hasta el día de hoy. El otro día un señor que vino a la universidad dijo: «Esto que ven mírenlo porque en cinco años no existirá». Y va a seguir existiendo, porque no hay un mejor modelo que se haya logrado inventar para hacer algo masivo y socializante como es el papel de la educación. La educación no es solamente enseñar-aprender, es también socializar, lugar de encuentro y una fábrica de homogenización. Y para eso es magnífica para uniformarnos como sociedad. ¿Podría la Universidad cambiar? Sí. Pero la institución es tan jurásica que no va a cambiar.

JT: Y los medios tradicionales frente a los nuevos medios tecnológi$\cos \ldots$

OR: Pues lo que va a pasar es que hay una re-adecuación de los medios. Por ejemplo, la prensa es la que más sufre. El medio más jurásico que es la prensa es el que está siendo más tambaleado, con la tendencia de los nuevos medios porque ellos tenían el dominio sobre la opinión pública y ahora quedaron por un lado deslegitimados como lugar de opinión pública, y por otro lado banalizados demostrando que no tienen ninguna posición de autoridad cognitiva ni política sobre la sociedad. A la prensa le toca reinventarse para volver a ser algo distinto. Le toca 
reinventarse en función de su lugar cultural en la sociedad. La radio siempre ha estado al margen y ahí sobrevive. En la web hay muchas radios de internet con otra lógica. La televisión es otro medio jurásico que tiene que reinventarse pero no mucho, porque su lugar ritualístico no se lo compite nadie, no hay ningún otro lugar en la sociedad donde tú puedas relajarte como te relajas en televisión. Ver Youtube implica cierto activismo, cierto cambio. La televisión no te pide nada a cambio. Eso no lo está peleando nadie. Se va a bajar el rating a la mitad pero no va a pasar de eso. La explicación que hacemos los que pensamos sobre esto es que a la sociedad le cayó un meteorito. Como en la época de los dinosaurios. El meteorito se llamó «internet-red digitales celulares». Llegó y cambió el ecosistema. El dinosaurio más grande que era la prensa, tiene que convertirse en un colibrí, un pajarito que es heredero de este dinosaurio, pero que tiene que sobrevivir con ese tamaño. Lo mismo le pasa a la televisión. Tiene que transformarse en el nuevo ecosistema. Ya no vamos a tener dinosaurios ninguno, sino una cantidad de pajaritos herederos de ellos, de los cuales uno volará más alto, etc.

"La ciudad clásica era un lugar de todos, esto se perdió con la ciudad moderna, y ahora con las nuevas tecnologías hay muchas ciudades superpuestas.»

JT: Y este nuevo contexto en cuanto a la construcción de la ciudadanía, de lo que significa ser ciudadano y ciudadana... De las ciudades, de la forma de pensar y de repensar las ciudades....

OR: A mí me parece que todo es ganancia porque lo que la ciudad moderna había quitado era que había convertido la ciudad en circulación - como dice el profesor Jesús Martín Barbero - ... pasamos de una ciudad de encuentros a una ciudad de paso. La ciudad clásica era aquélla en la que te encontrabas en la calle y en la plaza pública. La ciudad moderna de finales del xx, es aquélla en la que lo que importaba eran las vías para circular y que los lugares de encuentro fueran para el consumo, el centro comercial (Mall) para consumir. Hoy con lo digital se han encontrado formas completamente nuevas de caminar la ciudad, de moverse por la ciudad y nuevas formas de encuentro en la ciudad.

"La cultura es el lugar de infección de las ciudades. Donde se encuentran las diferentes ciudades que no se quieren encontrar.» 
JT: Y de habitarla...

OR: De nuevos territorios para habitarla. Entonces digamos que se le quitó otra vez el monopolio al Mall y a la vía del auto como lugar fundamental de la ciudad. Esa parte está bien. La parte complicada es que la ciudad clásica era un lugar de todos, esto se perdió con la ciudad moderna, y ahora con las nuevas tecnologías hay muchas ciudades superpuestas: la ciudad de los jóvenes no es la misma que la de los niños, mujeres adultos o gays. Hay una construcción de multi-ciudades, que no se tocan. Habitamos la misma ciudad diez grupos humanos pero ninguno se toca con el otro, y entonces de alguna forma habría que buscar formas de interrumpir eso. Hay quien llama a eso «narrativas erráticas» para obligar a cruces, a infecciones entre las diferentes ciudades para que puedan funcionar. Y ahí es donde la cultura es maravillosa. La cultura es el lugar de infección de las ciudades. Donde se encuentran las diferentes ciudades que no se quieren encontrar. Eso es lo que hace un buen concierto, un buen festival, un buen carnaval. La otra infección es la política, y también puede hacer que la ciudad cool, la de los hipsters, se junte con la ciudad de los desahuciados, de los indignados, con la ciudad de los futuristas, de los anacrónicos, y que todos se junten. En el fondo, el virus que necesitamos es más política y más cultura para interrumpir esta fragmentación de ciudad.

EnriQue Salom (KULt-UR): Yo también creo que hay una ciudad ahora que no está tan planificada como en los diseños modernos de ciudad de Le Corbusier, donde las zonas de encuentros estaban reguladas en los planos. Y también le doy la razón a Manuel Delgado cuando explica que el poder político debería regular lo urbanístico y dejar lo urbano al uso de los ciudadanos, y lo que ocurre es que lo urbanístico se entrega al capital privado, y el poder político regula lo urbano, con reglamentos. Hago plazas duras para regular el uso que se pueda hacer de ellas, etc. Hay que reclamar lo vivo, lo urbano, lo vivo, lo rizomático.

OR: Hacerlo sin pedir permiso. Porque lo que implica la política es: ¿por qué pedir permiso para usar la ciudad? Y eso es político y cultural. Y por ello la cultura es maravillosa, porque te genera una emoción que inclusive a los políticos y a la represión le asusta meterse ahí. Si salimos todos y tomamos la calle y lo que hacemos es poesía y música durante una hora, la policía no te va a dar de piñas. Te va a preguntar. Y si haces arte por un ratito, te respetan porque todavía el ser humano entiende que en lo cultural hay el símbolo, y eso lo hace distinto. Si salgo y me tomo la ciudad y me pongo a protestar contra el sistema me 
van a dar de piñas porque dicen: «Este muchacho está interviniendo políticamente en la ciudad». Por lo tanto, hay que hacer la política desde otras prácticas, en otros lugares. Y ahi lo cultural es un lugar clave que realmente no lo hemos entendido. Y no lo hemos entendido ni los mismos que hacemos cultura porque seguimos reproduciendo las mismas lógicas clásicas de hacer cultura. No hemos sido capaces de lo que tú dices, mezclar de otros modos las ciudades; debemos bastardear las ciudades.

JT: El potencial de lo cultural o de la cultura como una herramienta performativa, también...

OR: Hacer de la cultura un acto performativo y hacer de la política un acto performativo también.

"La forma cultural de nuestro tiempo es el espectáculo. Lo que puedes hacer es estallar las formas conocidas de espectáculo, para que no haya una sola forma de espectáculo.»

ES: ¿Y dónde separamos el espectáculo de la cultura?

OR: Es que ya no se puede separar. La forma cultural de nuestro tiempo es el espectáculo. Lo que puedes hacer es estallar las formas conocidas de espectáculo, para que no haya una sola forma de espectáculo. No se trata de decir: «Esto es arte contra el espectáculo», sino que asumiendo las formas del espectáculo vamos a intervenir desde ahí dentro, porque es de ese gusto que nos van a consumir. Queremos por ejemplo hacer una protesta contra lo inhumano en la ciudad. Entonces salimos vestidos de mimo y hacemos un discurso y la gente nos va a mirar. Qué bonito. Si en cambio salimos y comenzamos a que todo el que se encuentre de frente le tiene que dar un beso al otro, de pronto la gente se siente así, pero pronto ven que está chévere y comienzan a construir una red de besos que atravesó siete kilómetros. Al otro día eso se vuelve noticia-espectáculo de los medios pero te pone a pensar si tú le darías un beso: «Me tocó enfrente un afro». $\mathrm{O}$ «me tocó darle un beso a un árabe». Te arma eso, pero no tienes que renunciar a la cultura-espectáculo, sino tomar la forma e intervenirla. Lo otro sería declararnos derrotados e incapaces de intervenir en esa lógica. Como si no pudiéramos jugar el partido en otra cancha. 
ES: No tanto derrotados sino ser considerados pasivos y no participantes.

OR: Sí, pero tampoco es bueno ser todo el tiempo participante. Todo eso que crea divisiones es un poco moralista. Y que hay que jugar siempre en las ambigüedades. Una veces ganaremos y otras perderemos pero hay que intervenir. Mientras nosotros sigamos dejando el espectáculo a la industria ellos van a estar felices. Entonces la actividad cultural financiada por el estado la hacemos entre cinco, nos reunimos los mismos cinco, nos sentimos super irreverentes, estamos en el mismo localito, hacemos el mismo arte, pero la sociedad misma que tiene que recibir un beneficio cultural no lo hace. Esta mañana hablábamos de un tema: en Andalucía hacen una campaña contra la ablación de clítoris de las mujeres árabes. Y se gastaron 60000 euros. No tienen que gastarse eso, porque eso no es un problema en Andalucía, pero como político eso te hace sentir comprometido. Comprometido con un problema de allá. Con los problemas de tu comunidad te lavas las manos y no intervienes. Por eso lo local es lo importante. Es lo local lo que te obliga a ser político, y no: «Estamos en contra de lo que ocurre en Palestina». Chévere, también estamos en contra de lo que ocurre en Palestina, pero a ver, ¿saliste a manifestarte, a poner el cuerpo, por lo que está pasando en tu comunidad? No. Ahí tenemos un problema político complicado y de cultura. De cultura política.

JT: Una cosa. Volviendo al territorio, a la ciudad, y a lo que algunos autores definían como «no lugares». ¿Lo ambiguo camina por ahí, transita?

OR: El concepto de «no lugar» es un concepto ambiguo, y daría cuenta de un espacio ambiguo. Un no lugar. Es un espacio que existe sin memoria. Un lugar sin identidad. El aeropuerto, que es un no lugar porque no tiene identidad, memoria ni nada. Pero yo lo habito con mi memoria y con mi lugar cultural que llevo a cuestas. Así que tampoco es un «no lugar» puro. Yo lo intervengo. Por más que vayamos a un Corte Inglés acá y lo veamos como un no lugar se interviene de alguna forma. En verano hay que tener en cuenta el gusto del español promedio para que compre en El Corte Inglés. Y cuando yo entro allí a comprar lo hago con mi lugar cultural, se vuelve entonces ambiguo. Es mucho más evidente con el migrante. El migrante entra en El Corte Inglés con su olor, con su vestimenta, con su color, aunque sea español de pasaporte. Y entra y deja de ser un «no lugar», está haciendo un lugar español pero habitado 
desde el lugar cultural migrante, su localia. A mí me interesan mucho más esos cruces porque son mucho más creativos y más divertidos.

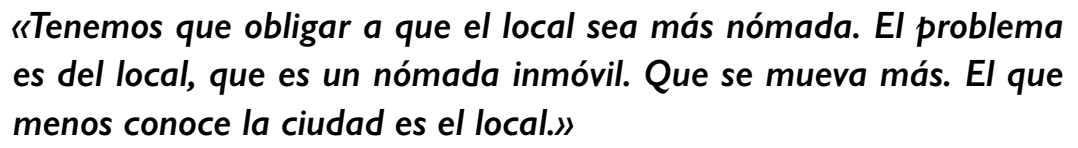

JT: Antes hablabas de que te había parecido sugerente esa idea de la mezcla, de esas miradas nómadas. ¿Cómo las ves en las ciudades? El concepto de extranjero en la ciudad invita a un cruce de miradas con lo nómada, y con lo local.

OR: El nomadismo lo que hace, que me interesa mucho, es, más que de la mirada del extranjero, de lo local. Tenemos que obligar a que el local sea más nómada. El problema es del local, que es un nómada inmóvil. Que se mueva más. El que menos conoce la ciudad es el local.

JT: Ahí pueden jugar un papel importante los medios: internet, la virtualidad... El trabajo de esa mirada más nómada.

OR: Sí, pero entonces nos vuelve muy cómodos. La televisión: tú no eres de Madrid, pero la televisión te construye una visión nómada de Madrid. Te dice qué lugares son pijos, qué lugares son peligrosos, y tú opinas de esa ciudad con eso que te construyó la televisión. Internet, a través de tus amigos que están allá, te construye otra ciudad territorialmente virtual en la cual también eres nómada. También internet te construye una mirada nómada de lo que pasa en el mundo. Todo eso está bien, pero el nomadismo habría que recuperarlo como tal, y no como turismo. Porque - esto lo saco a colación del examen del hijo de una amiga, donde le preguntaron «poblaciones humanas que van de sitio en sitio en busca de techo y de comida». Y el contestó «turistas». Y le pusieron un «mal» en el examen porque la respuesta esperada era «nómadas»— ésa es la diferencia: que si uno usa la palabra nómada es para no ser turista. La definición de turista es: «Aquél que viaja sin jamás querer verse implicado por lo que viaja». Con la seguridad de que volverá a casa tal cual.

JT: Con la vuelta cerrada y a qué hora toca cada cosa... 
OR: Con la seguridad de volver. El nómada es el que está dispuesto a perderse, producir experiencia, $\mathrm{y}$ al producir experiencia producir relato.

JT: Jurjo Torres hablaba del turista. Del curriculum del turista y del curriculum del viajante. Me imagino que utilizaba el concepto de viajante como «nómada».

OR: Exacto. Yo haría un test de nomadismo a un habitante de la ciudad. Pondré la cámara en el parque: «Cuénteme historias que le han pasado en esta ciudad». Si no tiene una historia es que no es un nómada porque no ha sido capaz de vivirla. La única forma de tener una historia es siendo nómada. El otro día contaba alguien que estaba de fiesta a las 5.00 a. m. y tuvo que atravesar cuarenta cuadras buscando un taxi. En eso llegó a su casa. Jamás había pensando llegar a su casa caminando. Y lo contaba como quejándose de la falta de taxis. Si hubiera encontrado un taxi se hubiera evitado esa experiencia nómada por la ciudad.

JT: Para vivir la ciudad hay que ser un poco nómada.

OR: No, tienes que ser nómada. No hay otra forma.

JT: ¿Entre lo rural y lo urbano? Las discontinuidades, la irrupción de los medios, de los no-medios...

OR: Yo creo que en América Latina el problema es distinto que en España y Europa. En América latina somos un continente rural que devino urbano por desarrollo y miedos. En el caso colombiano las violencias nos sacaron del campo, de lo rural, a la ciudad, y la ciudad se volvió un sitio desastroso, porque no está urbanizado, ni urbanístico, ni urbano, ni nada. El asunto complicado es que estas ciudades son habitadas todavía en clave rural. Y eso es distinto, una ciudad latinoamericana es muy caótica porque se habita bajo una lógica rural. No en una lógica urbana como NY, Berlín o Londres. Generacionalmente vamos a ir cambiando y creo que habrá al revés, los que son muy urbanos ahora quieren ser campesinos, pero no les podemos negar a los campesinos la utopía de querer ser urbanos. Él también tiene el derecho a vivir en la ciudad. Lo que hay es como unos cruces entre lo rural y lo urbano que es interesante cómo está pasando, cómo se está moviendo. Pero el caso latinoamericano sigue siendo complicado, el campo está en manos de terratenientes, la propiedad de la tierra tiene dificultad... la violencia tiene mucho que ver con la propiedad de la tierra, entonces lo que hacemos es hacer hacinados urbanos en condiciones que no son nada agradables. 